AperTO - Archivio Istituzionale Open Access dell'Università di Torino

Hole hopping rates in single strand oligonucleotides

This is a pre print version of the following article:

Original Citation:

Availability:

This version is available http://hdl.handle.net/2318/1589129

since 2021-09-13T12:02:51Z

Published version:

DOI:10.1016/j.chemphys.2014.05.010

Terms of use:

Open Access

Anyone can freely access the full text of works made available as "Open Access". Works made available under a Creative Commons license can be used according to the terms and conditions of said license. Use of all other works requires consent of the right holder (author or publisher) if not exempted from copyright protection by the applicable law. 
This Accepted Author Manuscript (AAM) is copyrighted and published by Elsevier. It is posted here by agreement between Elsevier and the University of Turin. Changes resulting from the publishing process - such as editing, corrections, structural formatting, and other quality control mechanisms - may not be reflected in this version of the text. The definitive version of the text was subsequently published in CHEMICAL PHYSICS, 440, 2014, 10.1016/j.chemphys.2014.05.010.

You may download, copy and otherwise use the AAM for non-commercial purposes provided that your license is limited by the following restrictions:

(1) You may use this AAM for non-commercial purposes only under the terms of the CC-BY-NC-ND license.

(2) The integrity of the work and identification of the author, copyright owner, and publisher must be preserved in any copy.

(3) You must attribute this AAM in the following format: Creative Commons BY-NC-ND license (http://creativecommons.org/licenses/by-nc-nd/4.0/deed.en), 10.1016/j.chemphys.2014.05.010

The publisher's version is available at:

http://linkinghub.elsevier.com/retrieve/pii/S0301010414001402

When citing, please refer to the published version.

Link to this full text:

http://hdl.handle.net/ 


\title{
Hole Hopping Rates in Single Strand Oligonucleotides
}

\author{
Raffaele Borrelli ${ }^{\mathrm{b}}$, Amedeo Capobianco $^{\mathrm{a}}$, Andrea Peluso ${ }^{\mathrm{a}, *}$ \\ ${ }^{a}$ Dipartimento di Chimica e Biologia, Università di Salerno, Via Giovanni Paolo II, \\ I-84084 Fisciano (SA), Italy \\ ${ }^{b}$ Dipartimento di Scienze Agrarie, Forestali e Alimentari, Università di Torino, Largo \\ Paolo Braccini 2, I-10095 Grugliasco (TO), Italy
}

\begin{abstract}
The rates of hole transfer between guanine and adenine in single strand DNA have been evaluated by using Fermi's golden rule and Kubo's generating function approach for the Franck-Condon weighted density of states. The whole sets of the normal modes and vibrational frequencies of the two nucleobases, obtained at DFT/B3LYP level of calculation, have been considered in computations. The results show that in single strand the pyramidalization/planarization mode of the amino groups of both nucleobases plays the major role. At room temperature, the Franck-Condon density of states extends over a wide range of hole site energy difference, $0-1 \mathrm{eV}$, giving some hints about the design of oligonucleotides of potential technological interest.
\end{abstract}

\section{Introduction}

Long distance charge transport in DNA has greatly fascinated researchers in the last two decades,[1, 2, 3, 4, 5, 6] both because it controls the site distribution at which oxidative damage takes place, and because its potential applications in molecular electronics and molecular computing.[7, 8, 9, 10] DNA has indeed found applications in nanoelectronics: thin metallic wires have been obtained by coating DNA with silver or by exchanging protons for doubly positive zinc ions inside the helix at high $\mathrm{pH}$ value.[7, 11] By using the intrinsic conducting properties of short DNA segments, a nanosize DNA transistor has also been obtained.[9]

\footnotetext{
${ }^{*}$ Corresponding author

Email address: apeluso@unisa.it (Andrea Peluso)
} 
Long range hole transfer (HT) in DNA has been extensively studied both by steady state and time resolved methods.[12, 13, 14, 15, 16, 17, 18, 19, 20, 21, 22, 23, 24, 25, 26, 27, 5] Photoionization followed by strand cleavage studies have shown that the oxidative damage is preeminently localized on guanine $(\mathrm{G})$, the nucleobase with the lowest oxidation potential, [28, 29, 30, 31,32 and that sequences consisting of two or more consecutive Gs are better hole traps than a single G.[12, 13, 14, 15, 16, 17, 18, 19, 20, 33] Furthermore, time resolved spectroscopical measurements have shown that although hole transfer is able to cover long distances along the duplex, $[1,2,4]$ the hopping process is in most of the cases slow, thus limiting potential applications to nano-scale electronic devices.[34, 35] Significant enhancement of the hole transport efficiency and rate has been observed both by including in the strand modified nucleobases which exhibit a lower oxidation potentials than natural nucleobases, or by using sequences consisting of blocks of homopurine sequences.[36, 37]

Many theoretical studies at very high level of sophistication have been performed in the past concerning the mechanism of HT in DNA.[38, 39, 40, 41, 42, 43, 44, 45, 46, 47, 48? ? ? Herein, stimulated by the recent report about the oxidation potentials of single strand oligonucleotides containing two or more consecutive As,[49] we report a theoretical analysis of the elementary HT step between G and A bases in single strands, with the aim of understanding a little more about the possible structural nucleobase properties which control HT in DNA, and the hope of obtaing useful hints for the rationale design of oligonucleotides, consisting prevalently of $\mathrm{G}$ and $\mathrm{A}$ bases, of potential interest in nanoelectronics. HT rates are computed by Fermi's Golden Rule in conjunction with Kubo's generating function method for evaluating the Franck-Condon weighted density of states, [50] an approach which in the past has been able to finely reproduce the temperature dependence of electron transfer from bacteriopheophytin to primary quinone in photosynthetic reaction centers. [51] The results show that the Franck-Condon weighted density of states extends over a broad range of the hole site energy difference, $\Delta E=0-1 \mathrm{eV}$; so that exoergic hole transfer is predicted to occur at subpicosecond rates in that whole energy difference range, whereas for endoergic processes such rates are predicted for $\Delta E$ up to $\approx 0.2 \mathrm{eV}$. 


\section{Theoretical approach and computational details}

Fermi's Golden rule expression of the rate of an electronic transition between two electronic states $|i\rangle$ and $|f\rangle$ is:

$$
k_{i f}=\frac{2 \pi}{\hbar}\left|V_{i f}\right|^{2} F_{i f}(\Delta E, T)
$$

where $V_{i f}$ is the electronic coupling element, which has been assumed in deriving Eq. 1 to be independent of vibrational coordinates, and $F_{i f}(\Delta E, T)$ is the Franck-Condon weighted density of states, given by:

$$
F_{i f}(\Delta E, T)=\frac{1}{Z} \sum_{v_{i}, v_{f}} e^{-\beta E v_{i}}\left|\left\langle v_{i} \mid v_{f}\right\rangle\right|^{2} \delta\left(E_{v_{f}}-E_{v_{i}}-\Delta E\right),
$$

where $E_{v_{i}}$ and $E_{v_{f}}$ are the energies of the vibrational states of the initial and final electronic state $|i\rangle$ and $|f\rangle$, respectively, $\Delta E$ is the electronic energy difference, $\left\langle v_{i} \mid v_{f}\right\rangle$ is the Franck-Condon integral, $Z$ is the vibrational partition function of the initial electronic state, $\beta=1 / k_{B} T$, and the sum runs over all vibrational states of $|i\rangle$ and $|f\rangle$.

The evaluation of $F(\Delta E, T)$ by use of multi-index recurrence relations [52, $53,54,55,56,57]$ poses problems for the extremely large amount of data which has to be stored.[58] From a computational point of view, the most efficient method for evaluating $F(\Delta E, T)$ is the generating function (GF) approach developed in the fifties by Lax and Kubo.[59, 50]

The GF approach is based on the integral representation of the delta function of Eq. 2, and on the coordinate representation of the vibrational Hamiltonian operators of the initial and final states, $\mathcal{H}_{i}$ and $\mathcal{H}_{f}$ in Eq. 4 below. In short, the approach consists in: i) writing $F(\Delta E, T)$ as the inverse Fourier transform of a correlation function $f(\tau)$

$$
F(\Delta E, T)=\frac{1}{2 \pi} \int_{-\infty}^{+\infty} \mathrm{e}^{\mathrm{i} \tau \Delta E} f(\tau) \mathrm{d} \tau
$$

where

$$
f(\tau)=\operatorname{Tr}\left\{\mathrm{e}^{-\mathrm{i} \tau \mathcal{H}_{f}} \mathrm{e}^{-(\beta-\mathrm{i} \tau) \mathcal{H}_{i}}\right\} / \operatorname{Tr}\left\{\mathrm{e}^{-\beta \mathcal{H}_{i}}\right\} ;
$$

ii) modeling $\mathcal{H}_{i}$ and $\mathcal{H}_{f}$ in harmonic approximation, with normal modes of vibration $\left(\mathbf{Q}_{i}\right.$ and $\left.\mathbf{Q}_{f}\right)$ differing for equilibrium positions, frequencies, and directions, and related each other by Duschinsky's transformation:

$$
\mathbf{Q}_{f}=\mathbf{J Q}_{i}+\mathbf{K}
$$


where $\mathbf{J}$ is the Duschinsky matrix, describing the mixing of normal modes upon transition from the initial to final electronic states, and $\mathbf{K}$ is the equilibrium position displacement vector; iii) integration over normal modes yields $f(\tau)$ from which $F(\Delta E, T)$ is computed by a discrete Fourier transform. Full details about implementation of the GF approach can be found in ref.s $[51,60,61]$; for its generalization to treat non-Condon effects see ref.s [? $62,63]$.

The diabatic states used here are defined as the electronic states with the positive charge fully localized on each molecular unit, i.e. $|i\rangle=\left|\mathrm{G}^{+} \mathrm{A}\right\rangle$ and $|f\rangle=\left|\mathrm{GA}^{+}\right\rangle$, and modeled as the direct product of the wave functions of the isolated molecules, $[64,51]$ so that $F(\Delta E, T)$ for the transition $\mathrm{G}^{+} \mathrm{A} \rightarrow \mathrm{GA}^{+}$ has been computed by the convolution of those referring to the two halfreactions: $\mathrm{G}^{+}+\mathrm{e}^{-} \rightarrow \mathrm{G}$ and $\mathrm{A} \rightarrow \mathrm{A}^{+}+\mathrm{e}^{-}$.

Equilibrium geometries, normal modes, and vibrational frequencies of $\mathrm{G}$ and $\mathrm{A}$ in their neutral and cationic form were obtained at DFT level using the standard B3LYP functional with the $6-311++\mathrm{G}(\mathrm{d}, \mathrm{p})$ basis set. Solvent (water) effects have been estimated by using the polarizable continuum model (PCM).[65] Geometry optimizations were also carried out at the (PCM)MP2/6-311++G(d,p) level. DFT and MP2 calculations have been performed by using the G09 package.[66] The $F(\Delta E, T)$ have been computed by using a development version of the MolFC package.[67, 57] The curvilinear coordinate representation of the normal modes has been adopted to prevent that a large displacement of an angular coordinate could reflect into large shifts of the equilibrium positions of the involved bond distances. That is unavoidable in rectilinear Cartesian coordinates and requires the use of high order anharmonic potentials for its correction.[68, 69, 70, 71, 72, 61]

\section{Franck-Condon factors and hole hopping rates}

The components of the equilibrium position displacement vectors $\mathbf{K}$ are by far the quantities which play a major role in determining the value and the shape of $F(\Delta E, T)$. The computed values of the components of $\mathbf{K}$ for the $\mathrm{G}^{+} / \mathrm{G}$ and $\mathrm{A} / \mathrm{A}^{+}$redox pairs are reported in Fig. 1 .

The displaced modes of Fig. 1 can be roughly grouped in three different classes. In the region between $400-800 \mathrm{~cm}^{-1}$ there are out of plane bending modes involving the two hydrogens of the amino group. In the region 800$1200 \mathrm{~cm}^{-1}$ there are in plane modes involving the ring heavy atoms, whereas 

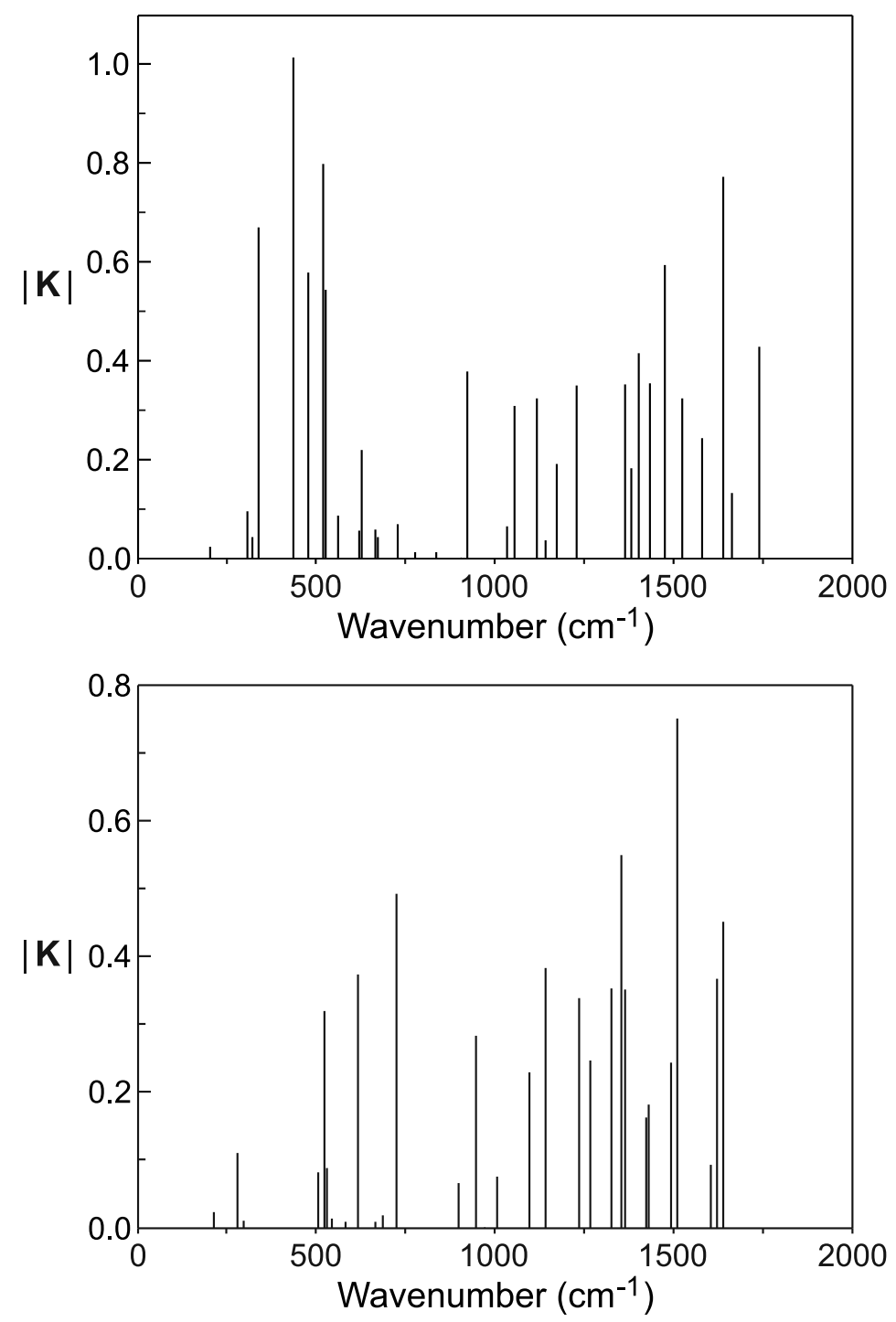

Figure 1: Dimensionless equilibrium position displacements of the normal modes of the $\mathrm{G} / \mathrm{G}^{+}$(upper panel) and of $\mathrm{A} / \mathrm{A}^{+}$(bottom panel) pairs.

in the region $1400-1700 \mathrm{~cm}^{-1}$ there are bending modes, involving ring and amino $\mathrm{H}$ atoms.

At variance with previous work,[73] the planarization of the exocyclic amino group is the most important geometrical change caused by nucleobase oxidation. In the case of neutral $\mathrm{G}$, the computed values of the out-of-plane 
bending of the $\mathrm{H}_{2 \mathrm{~b}}, \mathrm{H}_{2 \mathrm{a}}$ hydrogens, see Fig. 2, is 27.8 degrees whereas in the oxidized form the amino group is almost planar.[74] For $\mathrm{A}^{+}$the exocyclic amino group is also planar, whereas in the neutral form the out-of-plane bending of the $\mathrm{H}_{6 \mathrm{~b}}, \mathrm{H}_{6 \mathrm{a}}$ hydrogens of Fig. 2 is 13.2 degrees, respectively.
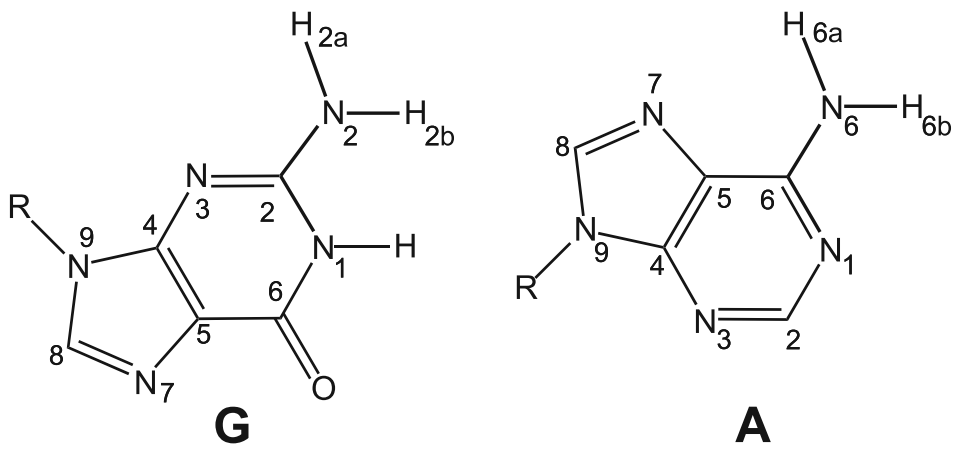

Figure 2: Atom numbering of $\mathrm{G}$ and $\mathrm{A}$.

MP2 computations confirm the above results; pyramidalization of the exocyclic amino group is predicted to be more pronounced with respect to DFT results: for $\mathrm{G}$ the out-of-plane bending considered above is 40.9 degrees, comparable to that obtained for A, 35.5 degrees, whereas both the cationic forms are predicted to be almost planar.

Noteworthy, pyramidalization of the amino group is also observed in BDNA: the average propeller twisted coordinate in B-DNA is ca. 16 degrees, [75] so that, as shown in Fig. 3 where the B-DNA X-ray average structures of A:T and G:C complexes are drawn, only a pyramidal configuration of the amino group, with dihedral angles comparable to those computed for the unpaired nucleobases, allows the amino hydrogen to lie on the line connecting the amino nitrogen of $\mathrm{G}$ and $\mathrm{A}$ to the carbonyl oxygen of cytosine $(\mathrm{C})$ and thymine $(\mathrm{T})$. Thus, although the geometries and the normal modes used here are better suited for treating hole hopping in single strands, the results are also somewhat representative of the situation in double helices.

Changes in the equilibrium bond distances and bond angles also contribute to the $\mathbf{K}$ vectors, but to a lesser extent: many $\mathrm{C}-\mathrm{C}$ and $\mathrm{C}-\mathrm{N}$ bonds change their equilibrium distances, but the displacements are not larger than $0.05 \AA$, whereas changes in the valence angles do not exceed 2.8 degrees, both for $\mathrm{G}^{+} / \mathrm{G}$ and $\mathrm{A} / \mathrm{A}^{+}$redox pairs. The computed B3LYP intramolecular reorganization energies, referring to the two isolated redox pairs in water, amount to 1622 and $2294 \mathrm{~cm}^{-1}$ for $\mathrm{A}$ and $\mathrm{G}$, respectively. 


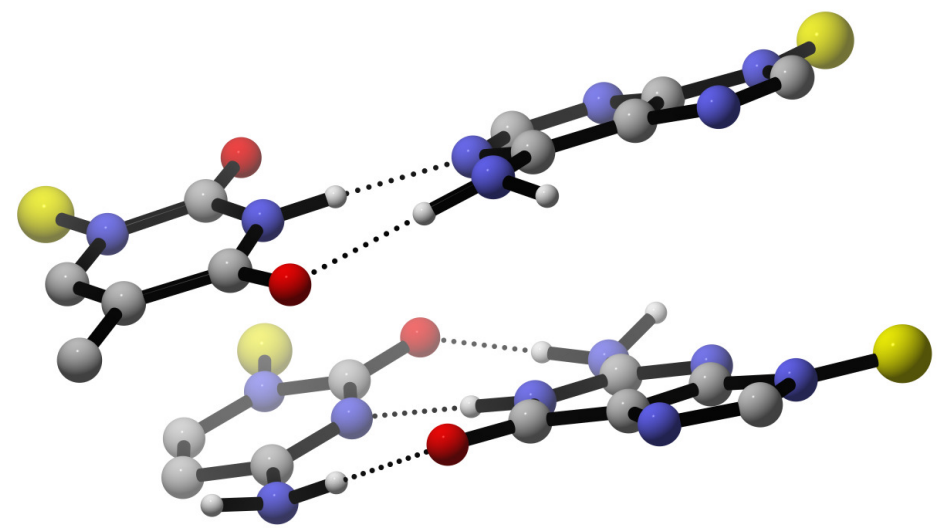

Figure 3: The A:T and G:C complexes in an average $\mathrm{X}$ ray structure of B-DNA. The $\mathrm{H}$-bonded hydrogens have been placed along the lines connecting heavy atoms.

The Franck-Condon weighted densities of states for the transition $\mathrm{GA}^{+} \rightarrow$ $\mathrm{G}^{+} \mathrm{A}$ at $T=77$ and $298 \mathrm{~K}$ are shown in Fig. 4 as a function of the energy difference between the initial and final states $(\Delta E)$. At $T=298 \mathrm{~K}, F(\Delta E, T)$ is a smooth curve peaked between $3200-3500 \mathrm{~cm}^{-1}$, whereas at low temperature it exhibits peaks, characteristic of a quantum system with a discrete set of quantum states, superimposed to a continuum which smoothly rises as $\Delta E$ rises, without reaching a maximum in the whole $\Delta E$ explored. There is a significant difference between the two $F(\Delta E, T)$ 's, indicating that the pre-exponential term is also temperature dependent, see below[76].

As concerns the electronic coupling term, experimental evidence and theoretical computations would suggest that it should be comprised in the range $0.05-0.3 \mathrm{eV}$, the largest value being that used for reproducing electron transport measurements and voltammetric measurements in tight binding calculations, [77, 78, 79, 49] whereas ab-initio calculations for B-DNA configurations yields significantly lower values. [41, 42, 43, 44]

Fermi's Golden Rule predicts that the exoergic HT from A A $^{+}$to $\mathrm{G}$ occur on subpicosecond timescale in the whole $\Delta E$ range, even for smaller electronic coupling elements; in the case of $V=0.05 \mathrm{eV}$,[44] $k_{A G}$ varies from $1 \cdot 10^{13}$ to $5 \cdot 10^{13}$ in the whole $\Delta E$ region of interest, $\Delta E=0-6000 \mathrm{~cm}^{-1}$.

The Fermi golden rule could not be very reliable to treat a very fast process as hole transfer from $\mathrm{G}^{+}$to $\mathrm{A}$ is. However, there are several indications in the literature that it provides a reasonable guess of the overall decay, in particular it has been shown that in large molecules with a high 


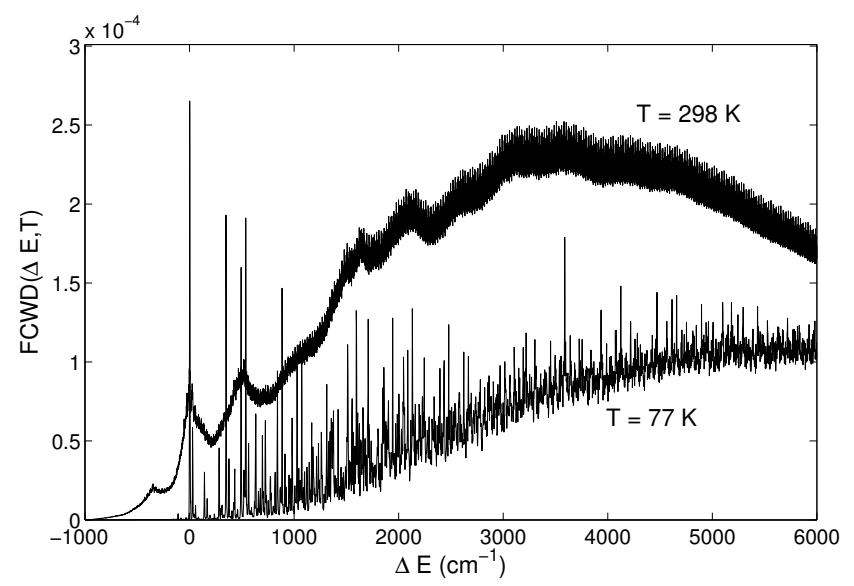

Figure 4: The Franck-Condon weighted density of states for the $\mathrm{A}^{+} \mathrm{G} \rightarrow \mathrm{AG}^{+}$transition, as a function of the electronic energy difference $\Delta E=E_{\mathrm{A}^{+} \mathrm{G}}-E_{\mathrm{AG}^{+}}$.

density of states the exponential decay provided by the Fermi golden rule is a reasonable approximation.[80, 81, 82] We remark that, given the situation yielded by Duschinsky's analysis - more than 50 displaced modes, of which at least 20 with a $\mathrm{K}$ component greater than 0.3 - a meaningful solution of the time-dependent Schrödinger equation is at the moment a formidable task. [64] Preliminary results using a more accurate treatment,[83] based on the second order cumulant approximation predict that ET from $\mathrm{A}+$ to $\mathrm{G}$ is slightly faster, work is still in progress along that line.

The rate of the reverse process $\mathrm{G}^{+} \mathrm{A} \rightarrow \mathrm{GA}^{+}$, obtained by the principle of detailed balance:[84, 85]

$$
k_{g a}=k_{a g} \exp \left[-\Delta E / k_{B} T\right],
$$

is reported in Fig. 5 as a function of $|\Delta E|$ for $V=0.1 \mathrm{eV}$. The energy difference between the initial and final HT states can be estimated from the oxidation potentials of the isolated nucleosides and their H-bonded complexes with the complementary bases in non polar solvents, all referred to the same ferrocene/ferrocenium internal standard.[28, 29, 30] The free energy cost to bring an electron hole from $\mathrm{G}$ to $\mathrm{A}$ is ca. $3000 \mathrm{~cm}^{-1}$ in single strand and rises to $3500 \mathrm{~cm}^{-1}$ in double strands, because of the effects of the pairing with the complementary nucleobases. $[28,29]$ By keeping $\Delta E=3000 \mathrm{~cm}^{-1}$, the computed $\mathrm{HT}$ rate for the $\mathrm{G}^{+} \mathrm{A} \rightarrow \mathrm{GA}^{+}$transition is $3.8 \cdot 10^{7} \mathrm{~s}^{-1}$ and $1.4 \cdot 10^{9}$ $s^{-1}$ for $\mathrm{V}=0.05$ and $0.3 \mathrm{eV}$, respectively. 


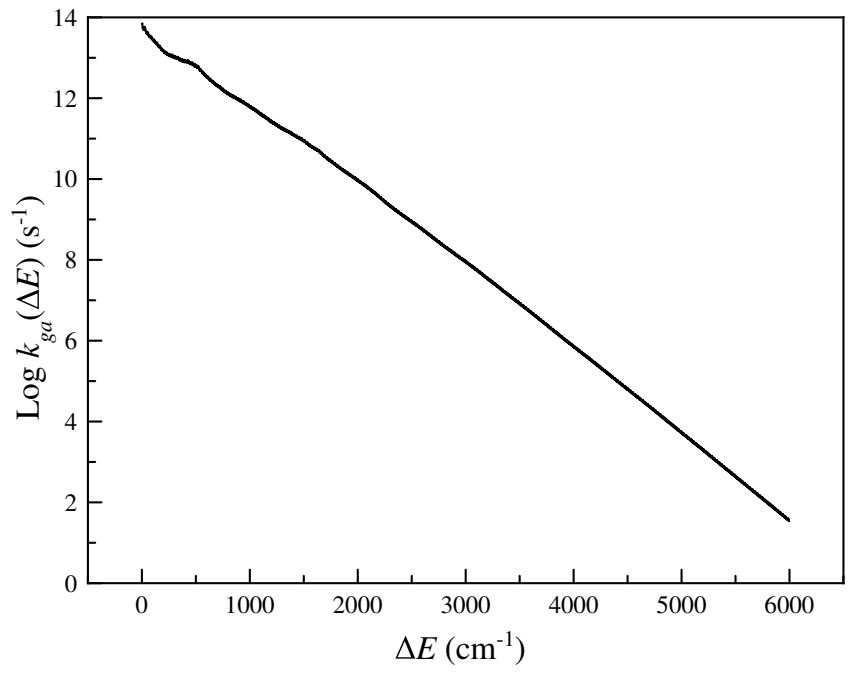

Figure 5: Rate constant for the $\mathrm{G}^{+} \mathrm{A} \rightarrow \mathrm{GA}^{+}$process as a function of the energy difference between diabatic states for $V=0.1 \mathrm{eV}$

The theoretical rate constants estimated so far are well representative of the general picture emerging from time dependent spectroscopical measurements, namely that HT in DNA is an inherently slow process, which takes place on timescales of nanoseconds or less.[34, 35] Furthermore, the very simple model used here provides a temperature dependence in fairly good agreement with the conductivity measurements of Tran et al., carried out in $\lambda$-DNA, found that conductivity is well described by the form $\sigma=\sigma_{0} e^{-\frac{\Delta}{2 k T}}$, with $\Delta \approx 0.3 \mathrm{eV}$.[76] Explain the temperature dependence of HT rates on temperature is far beyond our present objectives; our model predicts that the pre-exponential factor should also be a function of $\mathrm{T}$, further work along this line is in progress. Our analysis clearly shows that because of the exponential dependence of HT rates on $\Delta E$, hole site energies play the predominant role in long range HT. A decrease by $0.1 \mathrm{~V}$ in the oxidation potential of a shuttle site reflects into an increase by about two order of magnitude of the rate for hole injection in that state. Noteworthy, recent differential pulse voltammetry measurements have shown that the oxidation potentials of single strand oligonucleotides containing adenine (A) rich regions significantly decrease upon increasing the number of consecutive A units. [49] In the case of two consecutive As, voltammetric measurements indicate a decrease in the oxidation potential of the A pair by ca. $0.3 \mathrm{~V}$. If the wavefunction of a hole 
site consisting of two consecutive As can be written as the linear combination of states with a hole fully localized on a single A:

$$
\left|\mathrm{G}(\mathrm{AA})^{+}\right\rangle=\frac{1}{\sqrt{2}}\left(\left|\mathrm{GA}^{+} \mathrm{A}\right\rangle+\left|\mathrm{GAA}^{+}\right\rangle\right)
$$

the Franck-Condon weighted density of states for the injection of a hole into a pair of consecutive As can be well approximated by that of Fig. 4, because the additional $\langle\mathrm{A} \mid \mathrm{A}\rangle$ term is unity. By using the voltammetric data of Ref. [49] the predicted rate constant for hole injection from a single $\mathrm{G}$ into a pair of adjacent well stacked As $\left(\Delta E \approx 600 \mathrm{~cm}^{-1}\right)$ is four order of magnitude larger than for HT to a single A. Those considerations rely on the assumption that oxidation potential shifts are entirely attributed to the effects of stacking interactions between nucleobases in resonant conditions. Processes which could remove resonance conditions, i.e. the localizing effects of the solvent,[86] and the possible role of proton transfer, recently observed in A self aggregates, [87] which is known to play a role in the excited states dynamics of DNA base pairs, [88, 89] have to be deeper analyzed before drawing definitive conclusions.

\section{Conclusion}

The results reported here indicate that hole hopping from $G$ to a single $\mathrm{A}$ is a slow process, even in single strands where the higher geometrical flexibility could facilitate polaron motion.[35] Notwithstanding, the ability of A to form strong stacking interactions, with the possible formation of delocalized domains with a significant lower oxidation potentials, $[49,40]$ can significantly increase the hole hopping rates. The establishment of delocalized domains in DNA containing consecutive purine bases is a very debated issue. $[90,91,92,93,86,49]$ We have previously shown, that the largest delocalized domain which can favor hole transfer consists of about four adjacent adenine; longer sequences are not more effective and therefore long persistence length are not required. The theoretical analysis reported here shows that hole hopping through delocalized domains should occur at subpicosecond rates, a time sufficiently short for making a conformationally gated hopping mechanism operative;[93] ad hoc tailored single strands, in which single $\mathrm{G}$ are alternated by two or three As, are thus worthy of experimental investigation for applications in molecular electronics. 


\section{Acknowledgement}

This paper is dedicated to prof. Adolfo Zambelli on the occasion of his 80th birthday. The financial supports of MIUR (PRIN09) and of the University of Salerno are gratefully acknowledged.

\section{References}

[1] C. J. Murphy, M. R. Arkin, Y. Jenkins, N. D. Ghatlia, S. H. Bossmann, N. J. Turro, J. K. Barton, Science 262 (1994) 1025-1029.

[2] C. J. Murphy, M. R. Arkin, N. D. Ghatlia, S. H. Bossmann, N. J. Turro, J. K. Barton, Proc. Natl. Acad. Sci. USA 91 (1994) 5315-5319.

[3] G. B. Schuster, Acc. Chem. Res. 33 (2000) 253-260.

[4] B. Giese, Acc. Chem. Res. 33 (2000) 631-636.

[5] T. Takada, K. Kawai, M. Fujitsuka, T. Majima, Proc. Natl. Acad. Sci. USA 101 (2004) 14002-14006.

[6] J. C. Genereux, J. K. Barton, Chem. Rev. 110 (2010) 1642-1662.

[7] E. Braun, Y. Eichen, U. Sivan, G. Ben-Yoseph, Nature 391 (1998) 775778 .

[8] J.-J. Shu, Q.-W. Wang, K.-Y. Yong, Phys. Rev. Lett. 106 (2011) 188702.

[9] K.-H. Yoo, D. H. Ha, J.-O. Lee, J. W. Park, J. Kim, J. J. Kim, H.-Y. Lee, T. Kawai, H. Y. Choi, Phys. Rev. Lett. 87 (2001) 198102.

[10] R. G. Endres, D. L. Cox, R. R. P. Singh, Rev. Mod. Phys. 76 (2004) $195-214$.

[11] A. Rakitin, P. Aich, C. Papadopoulos, Y. Kobzar, A. S. Vedeneev, J. S. Lee, J. M. Xu, Phys. Rev. Lett. 86 (2001) 3670-3673.

[12] O. I. Kovalsky, I. G. Panyutin, E. I. Budowsky, Photochem. Photobiol. 52 (1990) 509-517.

[13] I. Saito, M. Takayama, H. Sugiyama, K. Nakatani, A. Tsuchida, M. Yamamoto, J. Am. Chem. Soc. 117 (1995) 6406-6407. 
[14] H. Sugiyama, I. Saito, J. Am. Chem. Soc. 118 (1996) 7063-7068.

[15] J. G. Muller, R. P. Hickerson, R. J. Perez, C. J. Burrows, J. Am. Chem. Soc. 119 (1997) 1501-1506.

[16] K. Nakatani, K. Fujisawa, C. Dohno, T. Nakamura, I. Saito, Tetrahedron Lett. 39 (1998) 5995-5998.

[17] Y. Yoshioka, Y. Kitagawa, Y. Takano, K. Yamaguchi, T. Nakamura, I. Saito, J. Am. Chem. Soc. 121 (1999) 8712-8719.

[18] R. P. Hickerson, F. Prat, J. G. Muller, C. S. Foote, C. J. Burrows, J. Am. Chem. Soc. 121 (1999) 9423-9428.

[19] K. Nakatani, C. Dohno, I. Saito, J. Am. Chem. Soc. 122 (2000) 58935894.

[20] B. Giese, S. Wessely, Angew. Chem. Int. Ed. 39 (2000) 3490-3494.

[21] C. Wan, T. Fiebig, O. Schiemann, J. K. Barton, A. H. Zewail, Proc. Natl. Acad. Sci. USA 97 (2000) 14052-14055.

[22] F. Lewis, X. Liu, S. Miller, R. T. Hayes, M. Wasielewski, Nature 406 (2000) 51-53.

[23] F. Lewis, R. Letsinger, M. Wasielewski, Acc. Chem. Res. 34 (2) (2001) $159-170$.

[24] S. Hess, M. Götz, W. B. Davis, M. E. Michel-Beyerle, J. Am. Chem. Soc. 123 (2001) 10046-10055.

[25] F. Lewis, X. Liu, S. Miller, R. T. Hayes, M. Wasielewski, J. Am. Chem. Soc. 124 (2002) 4568-4569.

[26] F. Lewis, J. Liu, X. Zuo, R. T. Hayes, M. Wasielewski, J. Am. Chem. Soc. 125 (2003) 4850-4861.

[27] T. Takada, K. Kawai, S. Tojo, T. Majima, J. Phys. Chem. B 107 (2003) 14052-14057.

[28] T. Caruso, M. Carotenuto, E. Vasca, A. Peluso, J. Am. Chem. Soc. 127 (2005) 15040-15041. 
[29] T. Caruso, A. Capobianco, A. Peluso, J. Am. Chem. Soc. 129 (2007) 15347-15353.

[30] A. Capobianco, M. Carotenuto, T. Caruso, A. Peluso, Angew. Chem. Int. Ed. 48 (2009) 9526-9528.

[31] M. Faraggi, F. Broitman, J. B. Trent, M. H. Klapper, J. Phys. Chem. 100 (1996) 14751-14761.

[32] X. Yang, X.-B. Wang, E. R. Vorpagel, L.-S. Wang, Proc. Natl. Acad. Sci. USA 101 (2004) 17588-17592.

[33] F. Lewis, X. Liu, J. Liu, R. T. Hayes, M. Wasielewski, J. Am. Chem. Soc. 122 (2000) 12037-12038.

[34] K. Kawai, T. Majima, Acc. Chem. Res. 46 (2013) 26916-2625.

[35] A. K. Thazhathveetil, A. Trifonov, M. R. Wasielewski, F. D. Lewis, J. Am. Chem. Soc. 133 (2011) 11485-11487.

[36] K. Kawai, H. Kodera, Y. Osakada, T. Majima, Nat. Chem. 1 (2009) 156-159.

[37] J. Vura-Weis, M. R. Wasielewski, A. K. Thazhathveetil, F. D. Lewis, J. Am. Chem. Soc. 131 (2009) 9722-9727.

[38] J. Jortner, M. Bixon, T. Langenbacher, M. E. Michel-Beyerle, Proc. Natl. Acad. Sci. USA 95 (1998) 12759-12765.

[39] M. Bixon, B. Giese, S. Wessely, T. Langenbacher, M. E. Michel-Beyerle, J. Jortner, Proc. Natl. Acad. Sci. USA 96 (1999) 11713-11716.

[40] A. Voityuk, J. Jortner, M. Bixon, N. Rösch, Chem. Phys. Lett. 324 (2000) 430-434.

[41] A. Voityuk, J. Jortner, M. Bixon, N. Rösch, J. Chem. Phys. 114 (2001) 5614-5620.

[42] A. Troisi, G. Orlandi, J. Phys. Chem. B 106 (2002) 2093-2101.

[43] K. Senthilkumar, F. C. Grozema, C. F. Guerra, F. M. Bickelhaupt, L. D. A. Siebbeles, J. Am. Chem. Soc. 125 (2003) 13658-13659. 
[44] K. Senthilkumar, F. C. Grozema, C. F. Guerra, F. M. Bickelhaupt, F. D. Lewis, Y. A. Berlin, M. A. Ratner, L. D. A. Siebbeles, J. Am. Chem. Soc. 127 (42) (2005) 14894-14903.

[45] F. C. Grozema, S. Tonzani, Y. A. Berlin, G. C. Schatz, L. D. A. Siebbeles, M. A. Ratner, J. Am. Chem. Soc. 130 (2008) 5157-5166.

[46] F. C. Grozema, S. Tonzani, Y. A. Berlin, G. C. Schatz, L. D. A. Siebbeles, M. A. Ratner, J. Am. Chem. Soc. 131 (40) (2009) 14204-14205.

[47] N. Reanaud, Y. A. Berlin, F. Lewid, M. A. Ratner, J. Am. Chem. Soc. 135 (2013) 3953-3963.

[48] Y. A. Berlin, I. V. Kurnikov, D. Beratan, M. A. Ratner, A. L. Burin, Top. Curr. Chem. 237 (2004) 1-36.

[49] A. Capobianco, T. Caruso, M. Celentano, A. M. D'Ursi, M. Scrima, A. Peluso, J. Phys. Chem. B 117 (2013) 8947-8953.

[50] R. Kubo, Y. Toyozawa, Prog. Theor. Phys. 13 (1955) 160-182.

[51] R. Borrelli, A. Peluso, Phys. Chem. Chem. Phys. 13 (10) (2011) 44204426.

[52] T. E. Sharp, K. M. Rosenstock, J. Chem. Phys. 41 (1964) 3453.

[53] A. Warshel, M. Karplus, Chem. Phys. Lett. 17 (1972) 7-14.

[54] E. V. Doktorov, I. A. Malkin, V. I. Man’ko, J. Mol. Spectosc. 64 (1977) 302.

[55] A. Peluso, F. Santoro, G. Del Re, Int. J. Quant. Chem. 63 (1997) 233244.

[56] A. Hazra, M. Nooijen, Int. J. Quant. Chem. 95 (4-5) (2003) 643-657.

[57] R. Borrelli, A. Peluso, J. Chem. Phys. 119 (2003) 8437-8448.

[58] R. Borrelli, A. Peluso, J. Chem. Phys. 129 (6) (2008) 064116.

[59] M. Lax, J. Chem. Phys. 20 (1952) 1752. 
[60] R. Borrelli, A. Peluso, Wiley Interdisciplinary Reviews: Computational Molecular Science.

[61] R. Borrelli, A. Capobianco, A. Peluso, Can. J. Chem. 91 (2013) 495-504.

[62] Y. Niu, Q. Peng, C. Deng, X. Gao, Z. Shuai, J. Phys. Chem. A 114 (30) (2010) 7817-7831.

[63] Q. Peng, Y. Yi, Z. Shuai, J. Shao, J. Chem. Phys. 126 (11) (2007) 114302-8.

[64] R. Borrelli, M. Di Donato, A. Peluso, Biophys. J. 89 (2005) 830-841.

[65] J. Tomasi, B. Mennucci, R. Cammi, Chem. Rev. 105 (2005) 2999-3094.

[66] M. J. Frisch, G. W. Trucks, H. B. Schlegel, G. E. Scuseria, M. A. Robb, J. R. Cheeseman, G. Scalmani, V. Barone, B. Mennucci, G. A. Petersson, H. Nakatsuji, M. Caricato, X. Li, H. P. Hratchian, A. F. Izmaylov, J. Bloino, G. Zheng, J. L. Sonnenberg, M. Hada, M. Ehara, K. Toyota, R. Fukuda, J. Hasegawa, M. Ishida, T. Nakajima, Y. Honda, O. Kitao, H. Nakai, T. Vreven, J. A. Montgomery, Jr., J. E. Peralta, F. Ogliaro, M. Bearpark, J. J. Heyd, E. Brothers, K. N. Kudin, V. N. Staroverov, R. Kobayashi, J. Normand, K. Raghavachari, A. Rendell, J. C. Burant, S. S. Iyengar, J. Tomasi, M. Cossi, N. Rega, J. M. Millam, M. Klene, J. E. Knox, J. B. Cross, V. Bakken, C. Adamo, J. Jaramillo, R. Gomperts, R. E. Stratmann, O. Yazyev, A. J. Austin, R. Cammi, C. Pomelli, J. W. Ochterski, R. L. Martin, K. Morokuma, V. G. Zakrzewski, G. A. Voth, P. Salvador, J. J. Dannenberg, S. Dapprich, A. D. Daniels, Ö. Farkas, J. B. Foresman, J. V. Ortiz, J. Cioslowski, D. J. Fox, Gaussian 09 Revision D.01, gaussian Inc. Wallingford CT 2009.

[67] R. Borrelli, A. Peluso, MolFC: A program for FranckCondon integrals calculation, package available online at http://www.theochem.unisa.it.

[68] R. Borrelli, A. Peluso, J. Chem. Phys. 125 (2006) 194308-194315.

[69] R. Borrelli, A. Peluso, J. Chem. Phys. 139 (2013) 159902.

[70] A. Peluso, R. Borrelli, A. Capobianco, J. Phys. Chem. A 113 (2009) 14831-14837. 
[71] A. Peluso, R. Borrelli, A. Capobianco, J. Phys. Chem. A 117 (2013) $10985-10985$.

[72] A. Capobianco, R. Borrelli, C. Noce, A. Peluso, Theor. Chem. Acc. 131 (2012) 1181.

[73] J. Olofsson, S. Larsson, J. Phys. Chem. B 105 (2001) 10398-10406.

[74] J. Leszczyński, Int. J. Quantum Chem. 44 (1992) 43-55.

[75] R. H. Garrett, C. M. Grisham, Biochemistry, 2nd ed., Brooks Cole, Ed., 1999.

[76] P. Tran, B. Alavi, G. Gruner, Phys. Rev. Lett. 85 (1564-1567).

[77] S. Roche, Phys. Rev. Lett. 91 (2003) 108101-108104.

[78] G. Cuniberti, L. Craco, D. Porath, C. Dekker, Phys. Rev. B. 65 (2002) 241314-4.

[79] D. Porath, A. Bezryadin, S. de Vries, C. Dekker, Nature 403 (2000) 635-638.

[80] A. Nitzan, J. Jortner, J. Chem. Phys. 58 (6) (1973) 2412-2434.

[81] W. Rhodes, J. Chem. Phys. 50 (7) (1969) 2885-2896.

[82] K. Takahashi, M. Yokota, Mol. Phys. 20 (4) (1971) 663-671.

[83] A. F. Izmaylov, D. Mendive-Tapia, M. J. Bearpark, M. A. Robb, J. C. Tully, M. J. Frisch, J. Chem. Phys. 135 (23) (2011) 234106-234106-14.

[84] H. Sumi, R. A. Marcus, Chem. Phys. Lett. 252 (1996) 85-91.

[85] T. Renger, R. A. Marcus, J. Phys. Chem. A 107 (2003) 8404-8419.

[86] S. M. Kravec, C. D. Kinz-Thompson, E. M. Conwell, J. Phys. Chem. B 115 (2011) 6166-6171.

[87] A. Capobianco, T. Caruso, M. Celentano, M. V. La Rocca, A. Peluso, J. Chem. Phys. 139 (2013) 145101.

[88] Z. Lan, L. M. Frutos, A. L. Sobolewski, W. Domcke, Proc. Natl. Acad. Sci. USA 105 (35) (2008) 12707-12712. 
[89] A. L. Sobolewski, W. Domcke, C. Hättig, Proc. Natl. Acad. Sci. U. S. A. 102 (2005) 17903-17906.

[90] D. M. Basko, E. M. Conwell, Phys. Rev. Lett. 88 (2002) 098102.

[91] L. Kurnikov, G. Tong, M. Madrid, D. Beratan, J. Phys. Chem. B 106 (2002) $7-10$.

[92] A. L. Burin, D. B. Uskov, J. Chem. Phys. 129 (2008) 025101.

[93] M. A. O’Neill, J. K. Burton, J. Am Chem. Soc. 126 (1985) 11471-11483. 